\title{
Day-to-day thermosphere parameter variation as deduced from Millstone Hill incoherent scatter radar observations during March 16-22, 1990 magnetic storm period
}

\author{
A. V. Mikhailov ${ }^{1}$ and M. Förster ${ }^{2}$ \\ ${ }^{1}$ Institute for Applied Geophysics, Moscow, Russia \\ ${ }^{2}$ GeoForschungsZentrum, Potsdam, Germany
}

Received: 4 November 1996 / Revised: 20 May 1997 / Accepted: 22 May 1997

\begin{abstract}
A self-consistent method for day-time F2region modelling was applied to the analysis of Millstone Hill incoherent scatter observations during the storm period of March 16-22, 1990. The method allows us to calculate in a self-consistent way neutral composition, temperature and meridional wind as well as the ionized species height distribution. Theoretically calculated $N_{e}(\mathrm{~h})$ profiles fit the observed daytime ones with great accuracy in the whole range of heights above $150 \mathrm{~km}$ for both quiet and disturbed days. The overall increase in $T_{\text {ex }}$ by $270 \mathrm{~K}$ from March 16 to March 22 reflects the increase of solar activity level during the period in question. A $30 \%$ decrease in $[\mathrm{O}]$ and a twofold increase in $\left[N_{2}\right]$ are calculated for the disturbed day of March 22 relative to quiet time prestorm conditions. Only a small reaction to the first geomagnetic disturbance on March 18 and the initial phase of the second storm on March 20 was found in $[\mathrm{O}]$ and $\left[N_{2}\right]$ variations. The meridional neutral wind inferred from plasma vertical drift clearly demonstrates the dependence on the geomagnetic activity level being more equatorward on disturbed days. Small positive F2-layer storm effects on March 18 and 20 are totally attributed to the decrease in the northward neutral wind but not to changes in neutral composition. A moderate (by a factor of 1.5) $\mathrm{O} /$ $N_{2}$ ratio decrease relative to the MSIS- 83 model prediction is required to describe the observed $N_{m} F 2$ decrease on the most disturbed day of March 22, but virtually no change of this ratio is needed for March 21 .
\end{abstract}

\section{Introduction}

Ionospheric F2-layer storm effects related to geomagnetic disturbances have been studied for some decades

Correspondence to: A. V. Mikhailov because of their great practical importance for $\mathrm{HF}$ radio communication. The temporal, as well as spatial, storm effect's appearance is dependent on the intensity of geomagnetic disturbance, local and universal time of SSC, season, latitude and longitude of the observational point. Incoherent scatter observations along with F2layer theoretical modelling provide an excellent opportunity for an F2-layer storm effect analysis and this is being conducted by scientists in the framework of the CEDAR program. Periods of low (Richards et al., 1989) and high (Buonsanto et al., 1992a; Richards et al., 1994b) solar activity were analyzed using Millstone Hill radar observations.

A 7-day interval of continuous observations in March 16-23, 1990 (high solar activity) comprises quiet (March 16-17) as well as highly disturbed (March 18, 20, 21) periods with $A_{p}=76$ on March 21. A comprehensive description of that observational interval and its theoretical interpretation is given in Buonsanto et al. (1992a) for the American sector with Millstone Hill data and in Förster et al. (1992) for the European sector with EISCAT and satellite data of the 'Active' experiment.

Millstone Hill radar overhead observations provide $N_{e}(h), T_{e}(h), T_{i}(h)$, and $V_{z}(h)$ values, which can be used for a comparison with theoretical model calculations. Such comparisons were conducted for September 1984 (Richards et al., 1989) and March 1990 (Richards et al., 1994b) disturbed periods. Despite the fact that rather sophisticated theoretical models were used in these analyses they failed to describe the observed negative phase of ionospheric storms. Taking into account vibrationally excited $\mathrm{N}_{2}{ }^{*}$, which in some publications (Richards et al., 1989; Pavlov, 1994) is considered as a plausible mechanism for the F2-layer negative storm effect, did not help for the periods in question. The FLIP model (Richards et al., 1994a, c) did not reproduce the observed factor of a 1.7 decrease in the day-time electron density for the September 1984 storm period (Richards et al., 1989) and factor of 4 in the day-time $N_{m} F 2$ decrease for the March 1990 disturbance (Richards et al., 1994b). Although taking into account $N_{2}{ }^{*}$ 
effects gets closer than the calculated $N_{m} F 2$ to the observed ones for the disturbed days during daytime hours, the difference still remains large for the most disturbed day of March 22 and the inclusion of $N_{2}{ }^{*}$ makes the overall agreement between calculated and observed $N_{m} F 2$ for the quiet days of March 18-20 even worse. So, it was stressed that the inclusion of vibrationally excited $N_{2}{ }^{*}$ actually worsens the agreement between modelling and observations (Richards et al., 1994b). The same conclusion concerning the worsening effect of including vibrationally excited $\mathrm{N}_{2}{ }^{*}$ into model calculations was obtained by Richards et al. (1994c) for Millstone Hill data analysis during the period of solar maximum. On the other hand, Pavlov and Buonsanto (1997) put the stress on the importance of taking into account vibrationally excited $N_{2}{ }^{*}$ to model the March 16-23 and April 6-12, 1990 disturbed periods.

The main obstacle to obtaining a satisfactory theoretical model description for the F2-layer negative storm effect consists in the proper choice of thermospheric parameters. All mentioned theoretical calculations are based on the empirical (i.e. statistical) MSIS-86 (Hedin, 1987) thermospheric model, which is not designed for the description of specific helio-geophysical conditions for a given day and especially during disturbed periods although first-order geomagnetic activity effects are included in MSIS models. A factor of 3 to 5 decrease in the atomic oxygen density to molecular density ratio at $300 \mathrm{~km}$ was needed to explain the observed decrease in electron density for the September 1984 storm period (Richards et al., 1989. The MSIS-86 neutral composition predictions for the severe storm on March 20-21, 1990 turned out to be insufficient to explain a factor of 4 depletion in the observed day-time $N_{m} F 2$ values. The studies conducted by Richards et al. (1994b) and Buonsanto (1995) indicate that successful modelling of F2-layer storms requires a better definition of the storm time inputs, especially of the neutral atmosphere.

On the other hand, neutral composition and temperature as well as vertical plasma drift, i.e. the main aeronomic parameters responsible for $N_{e}(h)$ distribution in the F-region, may be obtained from radar observations. These observed ionospheric parameters will allow us to describe the observed $N_{e}(h)$ height profile for the conditions in question with the best accuracy. It is not a new idea to use ionospheric, in particular incoherent scatter data, for the extraction of thermospheric parameters. Incoherent scatter measurements provide an excellent material for such estimates and they have been widely used for this purpose for years (Salah et al., 1974; Alcayde et al., 1974; Evans et al., 1979; Alcayde, 1979; Oliver, 1979, 1980, 1990; Ganguly et al., 1980; Alcayde and Fontanari, 1982; Lathuillere et al., 1983; Hagan and Oliver, 1985; Flå et al., 1986; Alcayde and Fontanari, 1986; Burnside et al., 1988; 1991b Belley et al., 1992; Buonsanto et al., 1992b; Oliver and Glotfelty, 1996).

The general approach is based on the use of the ion energy conservation equation in the F-region. This approach can provide valuable information on neutral temperature, atomic oxygen concentration and thermospheric winds. This method however, is not straight- forward. Experimental $T_{i}, T_{e}$ and to less extent $N_{e}$ depend upon the assumed model of ion composition. Usually it is presumed to be unchanged (at Millstone Hill and EISCAT, for instance) for various geophysical conditions and this should result in errors in experimental $T_{i}$ and $T_{e}$ values (Waldteufel, 1971; Lathuillere et al., 1983; Kirkwood et al., 1986; Winser et al., 1990; Glatthor and Hernandez, 1990) which are used to produce the energy equation solution. Further, the energy equation usually is considered for $\mathrm{O}^{+}$ions in an atmosphere consisting of atomic oxygen only (Alcayde and Fontanari, 1982; Burnside et al., 1988), or the whole neutral composition is taken from an empirical model (Alcayde and Fontanari, 1986; Winser et al., 1988; Glatthor and Hernandez, 1990). However, it is well known that ion composition changes with season and during geomagnetically disturbed periods. Neutral composition may differ from the empirical model predictions for the particular day chosen for the analysis. Nevertheless this approach is widely accepted and, for instance, such popular thermospheric models as the MSIS series are based on neutral temperature derived with the help of this method.

In our self-consistent approach (Mikhailov and Schlegel, 1997) we rely on $N_{e}(\mathrm{~h})$ height distribution as the most reliable parameter measured by the incoherent back-scatter facility to deduce thermospheric data. The traditional approach based on the ion energy conservation equation is used as well as a part of the method to find the area of possible inverse problem solution. Then this solution can be specified with the help of standard multiregressional methods. The method allows us to obtain, in a self-consistent way, such important thermospheric parameters as: concentrations of atomic [O] and molecular $\left[\mathrm{O}_{2}\right]$ oxygen, molecular nitrogen $\left[N_{2}\right]$, vertical plasma drift $\mathrm{W}$, exospheric temperature $T_{\mathrm{ex}}$ and shape parameter $\mathrm{S}$ for the $T_{n}$ height profile. It provides as well the $\mathrm{O}^{+}$ions flux in the topside F2-region as a result of the continuity equation solution. All these aeronomic parameters enable us to understand the physical reason for the observed F2-layer parameter changes in a particular geophysical situation.

The aim of this study is to analyze Millstone Hill daytime $N_{e}(h), T_{e}(h), T_{i}(h), V_{z}(h)$ observations and to estimate the main aeronomic parameters for the March 16-22, 1990 storm period. We will discover the reason for observed positive and negative F2-layer storm effects in the course of the period in question. As the method of calculation is supposed to deal with a stationary F2layer, only periods of relative stability in $N_{m} F 2$ and $h_{m} F 2$ variations around noon hours are analyzed.

\section{Method}

The self-consistent method of Mikhailov and Schlegel (1997) uses a standard set of incoherent scatter radar measured parameters and an F-region theoretical model to calculate the main aeronomic parameters responsible for the formation of $N_{e}(h)$ profile at F-region heights for daytime conditions. Unlike other similar methods the 
present one allows us to obtain neutral composition, temperature and vertical plasma drift in a self-consistent way.

The theoretical model of the mid-latitude F-region used in this method is described by Förster et al. (1995). It takes into account transport processes for $O^{+}\left({ }^{4} \mathrm{~S}\right)$ and photo-chemical processes only for $O^{+}\left({ }^{2} D\right), O^{+}\left({ }^{2} P\right)$, $\mathrm{O}_{2}^{+}\left(\mathrm{X}^{2} \Pi\right), \mathrm{N}_{2}^{+}$and $\mathrm{NO}^{+}$ions in the $120-620 \mathrm{~km}$ height range. Vibrationally excited $N_{2}$ effects are not taken into account explicitly in the model but the McFarland et al. (1973) $\mathrm{O}^{+}+\mathrm{N}_{2}$ reaction rate is presumed to mimic the increase of this reaction rate due to $\mathrm{N}_{2}{ }^{*}$ at high level of solar activity (Ivanov-Kholodny and Mikhailov, 1986). Observed electron concentration at $620 \mathrm{~km}$ is used as the upper boundary condition to solve the continuity equation for $O^{+}\left({ }^{4} \mathrm{~S}\right)$. At the lower boundary of 120 $\mathrm{km}$ the $\mathrm{O}^{+}\left({ }^{4} \mathrm{~S}\right)$ is supposed to be in a photo-chemical equilibrium. Experimental $T_{e}(\mathrm{~h})$ and $T_{i}(\mathrm{~h})$ profiles are used in the calculations.

Line-of-sight plasma velocity, $\mathrm{VO}$ is obtained from $80^{\circ}-90^{\circ}$ elevation angles and may be considered as total vertical plasma velocity, $V_{\mathrm{z}}(h)$. It includes the effects of thermospheric winds, electric field and plasma diffusion. These $V_{\mathrm{z}}(h)$ values should be "chirp corrected" before being used in calculations. The "chirp correction" is different for different experiments and equals $-11 \mathrm{~m} / \mathrm{s}$ for the March 16-22 period. Vertical plasma drift $\mathrm{W}$ is obtained from $V_{\mathrm{z}}(h)$ with the help of the expression (19.59) from Banks and Kockarts (1973)

$$
\begin{aligned}
W= & V_{\mathrm{z}}+\frac{k}{m_{i} \sum v_{i j}} \sin ^{2} I \\
& \left(T_{i} \frac{\partial \ln N_{i}}{\partial h}+T_{e} \frac{\partial \ln N_{e}}{\partial h}+\frac{g m_{i}}{k}+\frac{\partial\left(T_{e}+T_{i}\right)}{\partial h}\right)
\end{aligned}
$$

where $I$ is the magnetic field line inclination, $m_{i}$ - the $O^{+}$ ion mass, $T_{i}$ and $T_{e}$-ion and electron temperatures, $N_{i}$ and $\mathrm{N}_{e}$-ion $\mathrm{O}^{+}$and electron concentrations, $v_{i}$ - diffusion collision frequencies for $\mathrm{O}^{+}$related to momentum transfer collision frequencies $v^{*}$ by the expression (see Eq. 19.13 in Banks and Kockarts, 1973) $v_{i j}=m_{j} /\left(m_{i}+m_{j}\right) v_{i j}^{*}$ where $i$ applies to $O^{+}$ions and $j$ applies to other neutral or ionized gas species. Collisions of $\mathrm{O}^{+}$ions with neutral $\mathrm{O}, \mathrm{O}_{2}, \mathrm{~N}_{2}$ and $\mathrm{NO}^{+}, \mathrm{O}_{2}^{+}, \mathrm{N}_{2}{ }^{+}, \mathrm{N}^{+}$ ions are taken into account. All $\mathrm{O}^{+}$ion collision frequencies have been taken from Banks and Kockarts (1973). After subtraction of $V_{\perp N}$, which is the ion velocity component northward and perpendicular to the magnetic field due to $\mathbf{E} \times \mathbf{B}$ drift, the vertical plasma drift $\mathrm{W}$ can be exclusively attributed to the effects of thermospheric wind.

The temperature and concentrations of neutrals as well as the vertical plasma drift $\mathrm{W}$ are calculated in a self-consistent way in the $N_{e}(\mathrm{~h})$ fitting procedure. So, $T_{n}$, $[\mathrm{O}],\left[\mathrm{O}_{2}\right],\left[\mathrm{N}_{2}\right]$ and $\mathrm{W}$ are known at each step in order to solve the continuity equation for $\mathrm{O}^{+}$and the chemical balance equations for the other ions.

Likewise any non-linear multi-parametric inverse problem solution, the $N_{e}(\mathrm{~h})$ fitting procedure exhibits many local minima for $\Delta=\left[\log \left(N_{e}(h)_{\mathrm{obs}} / N_{e}(h)_{\mathrm{cal}}\right)\right]^{2}$ corresponding to pseudo-solutions and the problem is to choose one of them using additional physical constraints. The standard multi-regressional methods turn out to be inefficient to minimize $\Delta$ for the problem in question and a two-step procedure was developed to localize the minimum. When, after the first step, its approximate position is found then the standard methods may be applied to specify the final values for the parameters.

The first step is based on the use of the ion energy conservation equation in the F-region to find $T_{\mathrm{ex}}$. This is a widely used approach (see references cited in the Introduction). The only difference is that $[\mathrm{O}],\left[\mathrm{O}_{2}\right]$, and $\left[\mathrm{N}_{2}\right]$ used for $\mathrm{O}^{+}, \mathrm{NO}^{+}$and $\mathrm{O}_{2}^{+}$collision frequencies calculation are taken in a self-consistent way rather than from empirical models. Taking into account the molecular ions may be important for disturbed periods when their contribution becomes essential even at heights of the F2region. According to Banks and Kockarts (1973) the ion energy conservation equation may be written as follows:

$L_{\mathrm{ei}}+Q_{\text {in }}=0$

with

$$
\begin{aligned}
L_{\mathrm{ei}} & =3 k\left(T_{e}-T_{i}\right) \sum_{i=1}^{3} N_{i} v_{\mathrm{ie}} \\
Q_{\mathrm{in}} & =\sum_{i=1}^{3} \sum_{n=1}^{3} 3 k \frac{m_{i} N_{i} v_{\mathrm{in}}}{\left(m_{i}+m_{n}\right)}\left[\left(T_{n}-T_{i}\right)+\frac{m_{n}}{3 k}\left(\vec{C}_{i}-\vec{C}_{n}\right)^{2}\right]
\end{aligned}
$$

where: $\vec{C}_{i}$ and $\vec{C}_{n}$ are the ion and neutral velocity vectors, all other symbols are standard. The equation is solved in the $250-400 \mathrm{~km}$ height range to find the neutral temperature $T_{n}$ at each height step. These $T_{n}$ values are then used to calculate $T_{\mathrm{ex}}$ with the help of Bates (1959) expression:

$$
T_{\text {ex }}=\frac{T_{n}-T_{120} \exp \left[-S\left(h-h_{0}\right)\right]}{1-\exp \left[-S\left(h-h_{0}\right)\right]}
$$

where $T_{120}$ is the neutral temperature at $z_{0}=120 \mathrm{~km}$ taken from the MSIS-83 model (Hedin, 1983). The resultant $T_{\mathrm{ex}}$ is the average of all $T_{\mathrm{ex}}$ obtained in the 250$400 \mathrm{~km}$ height range. The frictional term can be considered as negligible, as long as relative drifts of ions with respect to the neutrals are smaller than about $300 \mathrm{~m} / \mathrm{s}$ as this gives an error in $T_{n}$ calculation less than $60 \mathrm{~K}$ (Alcayde and Fontanari, 1986). Such an accuracy is, in principle, quite sufficient for the first step of solution finding. On the other hand, daytime electric fields were small for the period in question (Buonsanto et al., 1992a), so the frictional term was ignored in Eq (2). The first step of $\Delta$ minimization gives the area of possible $T_{\text {ex }}, \mathrm{S},[\mathrm{O}],\left[\mathrm{O}_{2}\right],\left[\mathrm{N}_{2}\right]$ values, which are finally specified at the second step using a standard multi-regressional method with physical constraints on the parameters.

\section{Observations and calculations}

The list of periods along with solar and magnetic indices used in the study is given in Table 1.

The regime of observations provides about three overhead height $N_{e}, T_{e}, T_{i}$ and $V_{z}$ profiles per hour for the 
Table 1. List of time intervals of the March 1990 storm period used in the study. The three month average solar $10.7-\mathrm{cm}$ flux was $\overline{F_{10.7}}=184.1 \times 10^{-22} \mathrm{Wm}^{-2} \mathrm{~Hz}^{-1}$.

\begin{tabular}{llll}
\hline Date & $\begin{array}{l}\text { Time } \\
(\mathrm{UT})\end{array}$ & $\begin{array}{l}A_{p} \\
(\text { daily })\end{array}$ & $\begin{array}{l}F_{10.7} \\
(\text { day/day-1) }\end{array}$ \\
\hline 1990 & & & \\
Mar 16 & $18.0-21.0$ & 7 & $179.9 / 166.0$ \\
Mar 17 & $17.3-20.5$ & 3 & $183.8 / 179.9$ \\
Mar 18 & $16.5-19.5$ & 35 & $198.2 / 183.8$ \\
Mar 19 & $16.5-19.5$ & 16 & $218.2 / 198.2$ \\
Mar 20 & $16.5-19.5$ & 30 & $225.7 / 218.2$ \\
Mar 21 & $17.3-18.9$ & 76 & $229.3 / 225.7$ \\
Mar 22 & $18.4-20.0$ & 28 & $244.7 / 229.3$ \\
\hline
\end{tabular}

period in question, so we use at least a two-three hour period of observation (about 8-10 profiles) around the noon hours to calculate median profiles along with the standard deviations at each height. Of course, such a $3 \mathrm{~h}$ time interval for averaging is too long keeping in mind the $1.5 \mathrm{~h}$ characteristic time for the F2-layer maximum. But the scatter of the observed parameters is large for the disturbed days, so whenever possible we tried not to use shorter time intervals to produce more or less reliable profiles. These median vertical profiles are then smoothed by a polynom up to the 5 th degree before being used in the model calculations.
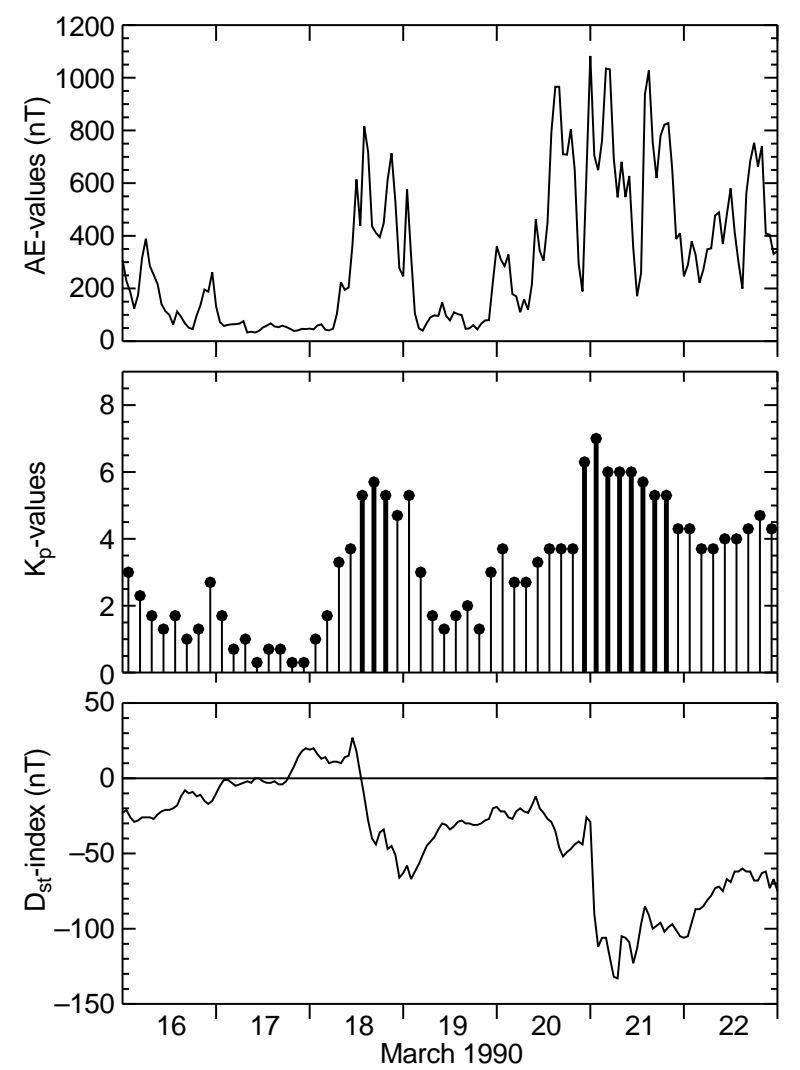

Fig. 1. Observed provisional $\mathrm{AE}, K_{p}$, and $D_{s t}$ indices variation versus universal time for the analyzed period of March 16-22, 1990
Figure 1 gives the variations of $\mathrm{AE}, K_{p}$ and $D_{\text {st }}$ indices for the period in question. The first magnetic storm with $\mathrm{AE}$ up to $800 \mathrm{nT}, K_{p}$ up to 5 and $D_{\text {st }}$ down to $-60 \mathrm{nT}$ on March 18 had its onset during daytime hours in the American sector. Magnetic activity returned to normal during the next day on March 19. The second and more severe magnetic storm with AE up to $1100 \mathrm{nT}$, $K_{p}$ up to 7 and $D_{\text {st }}$ down to $-130 n T$ had its SSC near 2245 UT on March 20, but the first splash of auroral activity was registered earlier (Fig. 1) again during daytime hours. This is important for further discussion. The geomagnetic activity decreased to some extent by March 22, but the ionosphere exhibited strong negative F2-layer storm effects on that day. March 17 was chosen as an excellent quiet time reference day.

The results of model calculations in comparison with the Millstone Hill $N_{e}(h)$ observations for the three most interesting days of March 18, 21 and 22, 1990 are shown in Figs. 2-4. The observed $N_{e}(h)$ profiles are given along with \pm standard deviations over the chosen period of observations. The quiet time $N_{e}(h)$ profile of March 17 is given as a reference. The observed median $T_{e}, T_{i}$ and $V_{z}$ profiles used in our calculations are given in Fig. 2 as for March 18 as an example.
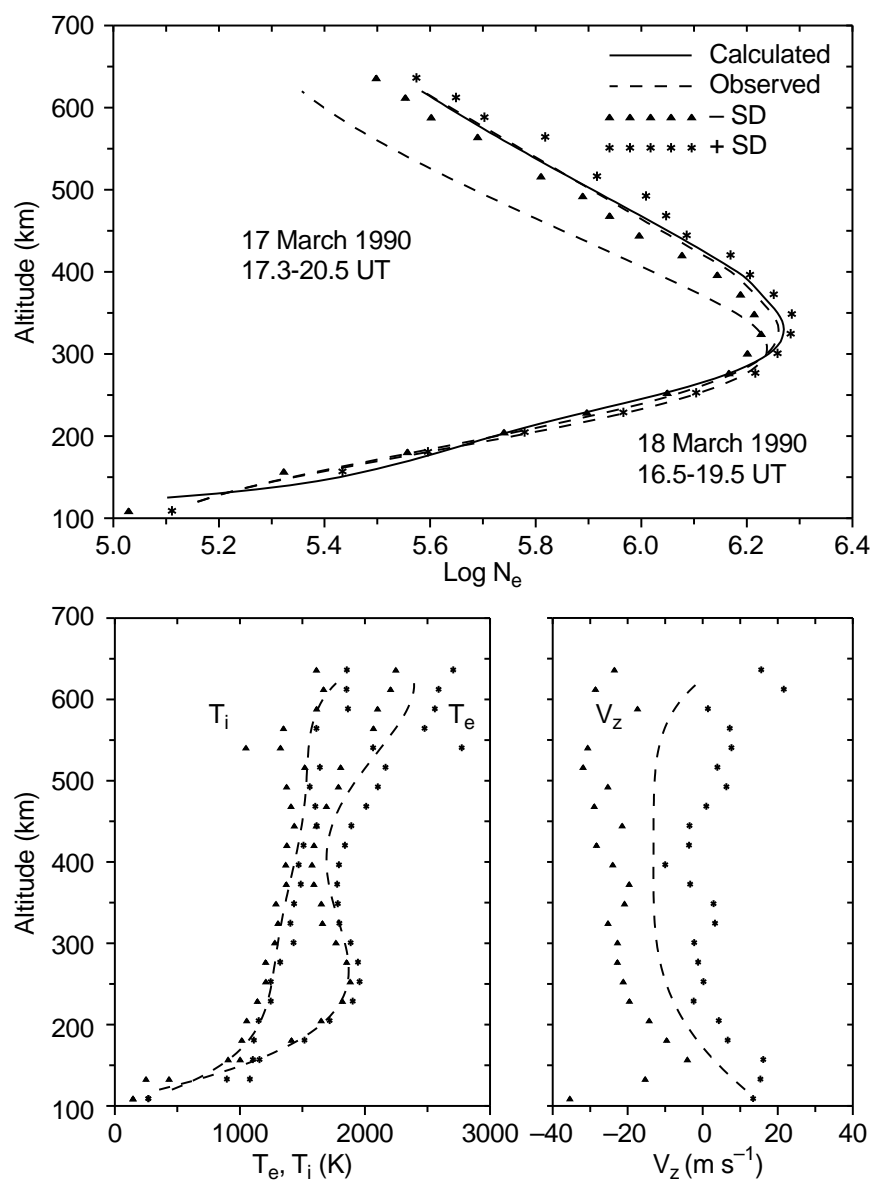

Fig. 2. Observed along with \pm standard deviations and calculated $N_{e}(\mathrm{~h})$ profiles for the disturbed day March 18, 1990 in comparison with the observed quiet time profile of March 17, 1990. Observed $T_{e}$, $T_{i}$ and $V_{z}$ along with \pm standard deviations median profiles used in our calculations are given in the lower boxes 

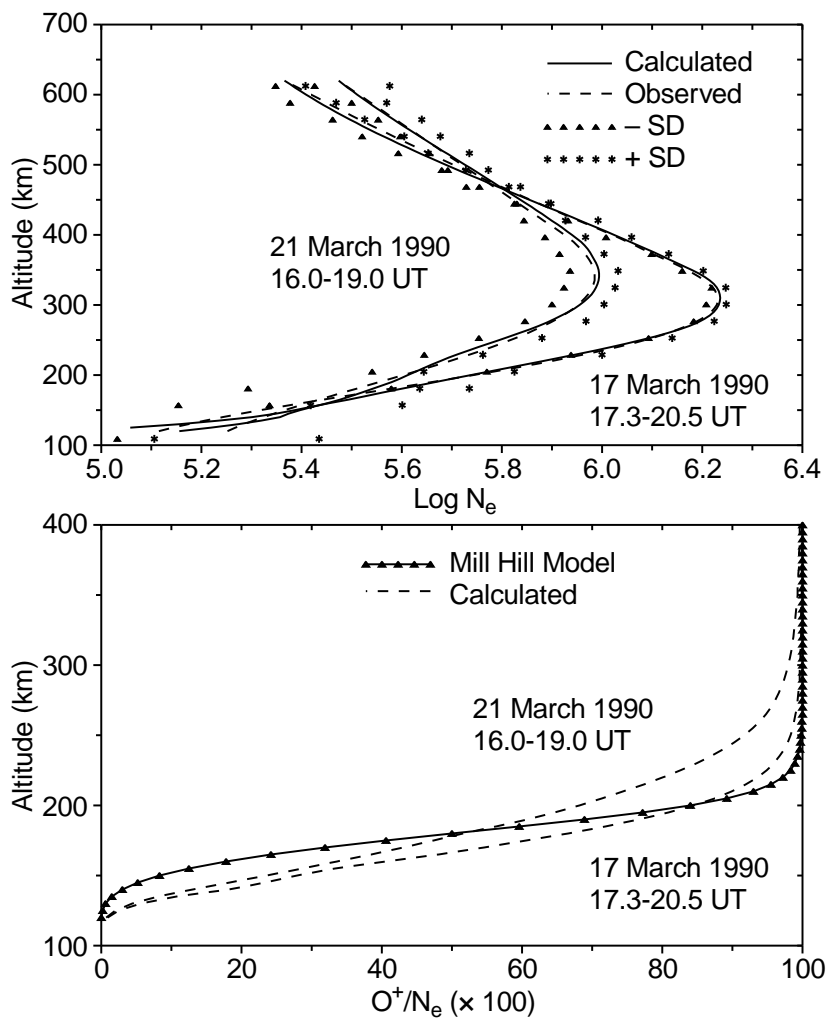

Fig. 3. Observed and calculated $N_{e}(\mathrm{~h})$ profiles for geomagnetically quiet March 17 and disturbed March 21, 1990 days (top panel). The standard deviations of the observed values are indicated. Calculated profiles closely match the observations on both days. Calculated $O^{+} /$ $N_{e}$ height variations are shown for the two days (bottom panel) and these are compared to the non-varying Millstone Hill standard ioncomposition model

A comparison of the calculated $O^{+} / N_{e}$ ratio with the standard Millstone Hill ion composition model is given in Figs. 3-4. The method is seen to provide a good fitting of the calculated to the observed $N_{e}(h)$ profiles in the whole range of heights above $150 \mathrm{~km}$ for both quiet and disturbed days.

Experimental $T_{e}(h), T_{i}(h)$ and $N_{e}(h)$ profiles derived from the incoherent scatter data analysis depend on the ion composition used in the fit of the theoretical to the measured auto-correlation function (ACF). An uncertainty in ion composition may lead to considerable uncertainties in the derived $T_{e}(\mathrm{~h})$ and $T_{i}(\mathrm{~h})$ profiles and to somewhat smaller uncertainties in $N_{e}(\mathrm{~h})$ (Waldteufel, 1971; Lathuillere et al., 1983; Kirkwood et al., 1986; Winser et al., 1990; Glathor and Hernandez, 1990). The most pronounced changes in ion composition take place during disturbed periods and in such conditions some iterations are required to obtain the proper fit to the measured ACF (Mikhailov and Schlegel, 1997). Such a correction applied to the two most disturbed days of March 21 and 22 has shown that the experimental profiles may not be corrected for March 21 as the changes in ion composition are not very strong (Fig. 3). Only one additional iteration was required for the March 22 experimental profiles. In the $200-250 \mathrm{~km}$ height range, where the difference in ion composition is
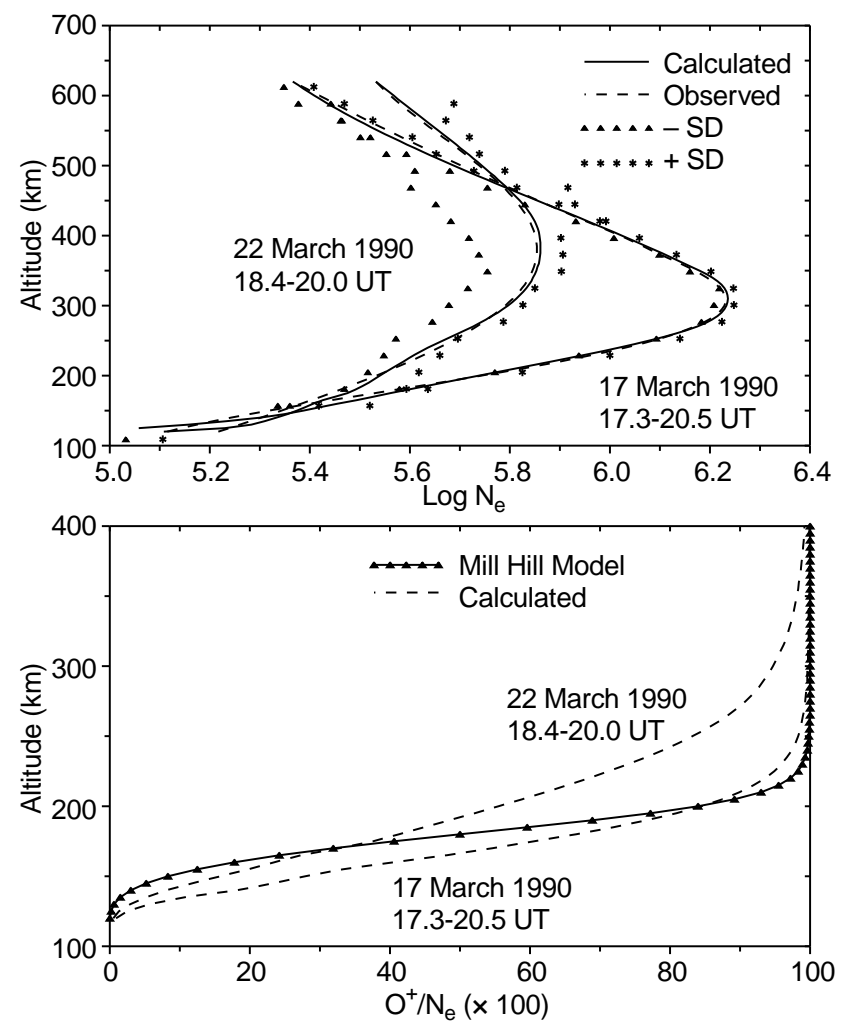

Fig. 4. Same as Figure 3 but for the disturbed day of March 22, 1990

the largest (Fig. 4), the corrected values are higher than the initial ones by $140 \mathrm{~K}$ for $T_{i}$, by $450 \mathrm{~K}$ for $T_{e}$ and by only $4 \%$ for $N_{e}$. These corrected profiles for March 22 were used in our further analysis. For more severe disturbances analyzed by Mikhailov and Schlegel (1997); and Mikhailov and Foster (1997) when the ionosphere was molecular-ion dominated up to 250-350 $\mathrm{km}$ a similar correction of the experimental profiles was much more important.

The observed day-to-day variations of the F2-layer maximum parameters are shown in Fig. 5. The slight $N_{m} F 2$ positive storm effect on March 18 resulted from the first geomagnetic disturbance (see Fig. 1) is accompanied by a $20 \mathrm{~km} h_{m} F 2$ increase. Day-time $N_{m} F 2$ and $h_{m} F 2$ values on March 19 practically returned to their prestorm values. A slight increase in $N_{m} F 2$ and a $40 \mathrm{~km}$ increase in $h_{m} F 2$ again take place at the beginning of the second storm on March 20 followed by pronounced negative storm effects on March 21 and 22 when the storm was in progress. The observed changes in $N_{m} F 2$ and $h_{m} F 2$ on March 22 relative to the prestorm reference March 17 level are a factor of 2.4 and $76 \mathrm{~km}$, correspondingly.

The four lower boxes in Fig. 5 give the ratio of the calculated $O^{+}$ion production rate $\mathrm{q}\left(O^{+}\right)$to the linear loss coefficient $\beta$, the $[\mathrm{O}] /\left[N_{2}\right]$ ratio, the $O^{+}$ion outflow at $600 \mathrm{~km}$ in comparison with Millstone Hill observations, and the vertical plasma drift $\mathrm{W}$ at the height of the F2-layer maximum. These are the most important aeronomic parameters responsible for the F2-layer maximum formation. A comparison of the $[\mathrm{O}] /\left[N_{2}\right]$ ratio to the MSIS-83 model prediction is given as well. 

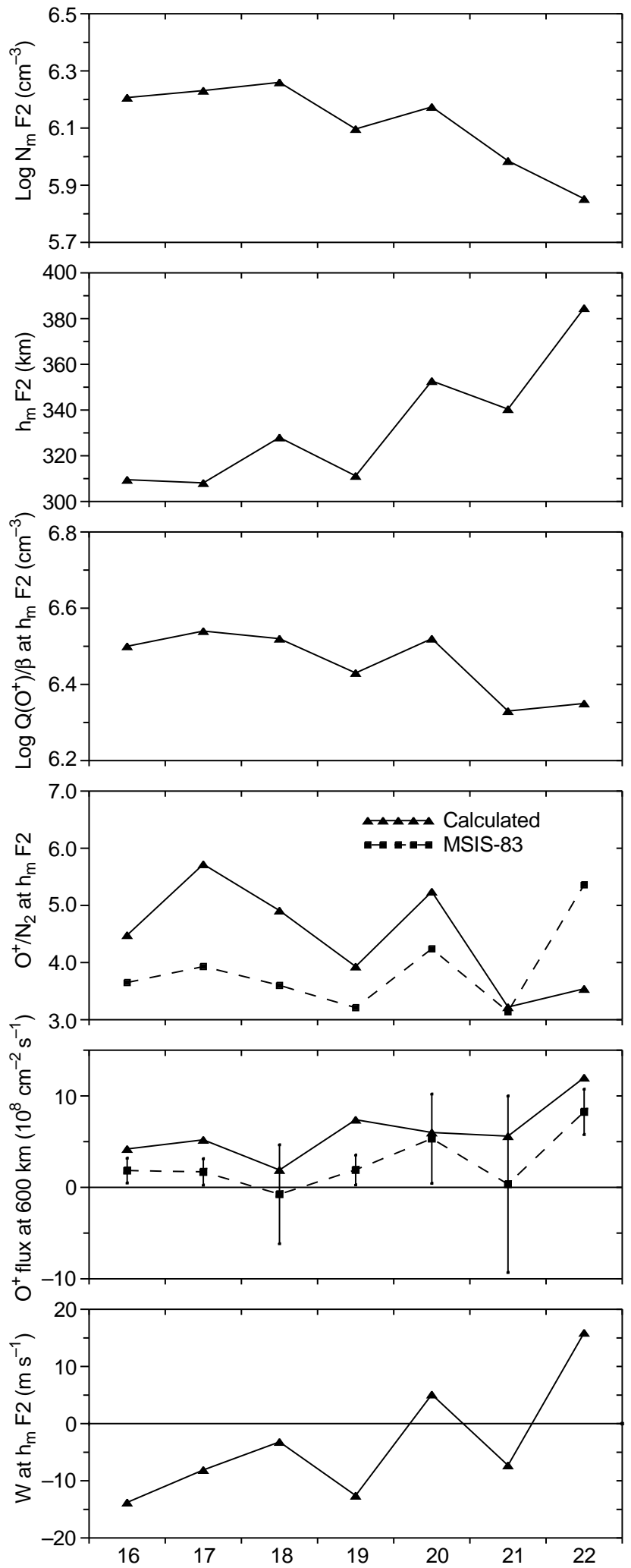

Fig. 5. Observed $\log N_{m} F 2$ and $h_{m} F 2$ variations for the March 16-22, 1990 period, calculated $\log \mathrm{q}\left(O^{+}\right) / \beta, \mathrm{O} / N_{2}$ ratios and vertical plasma drift at the height of F2-layer maximum as well as $O^{+}$ion outflow at $600 \mathrm{~km}$, compared to the Millstone Hill estimates (dashes) given along with standard deviations. MSIS- 83 model $\mathrm{O} / N_{2}$ prediction is shown for comparison (dashes). Calculated $\mathrm{W}$ values are given in the lower box. Figures along the $\mathrm{x}$ axis (UT) are dates of March 1990
Figure 6 gives the results of the thermospheric parameter calculations in comparison with the MSIS83 model predictions and Millstone Hill estimates. The exospheric temperature $T_{\mathrm{ex}}$ shows a general increase mostly resulted from the increase of solar activity level during the period in question (see Table 1). The calculated $T_{\mathrm{ex}}$ is close to the Millstone Hill $T_{\mathrm{ex}}$ estimates and both are higher than the MSIS- 83 predictions by $50-$ $130 \mathrm{~K}$ (Table 2). The calculated atomic oxygen [O] concentrations are pretty close to the MSIS- 83 predictions, but $\left[N_{2}\right]$ and $\left[O_{2}\right]$ are systematically lower at a
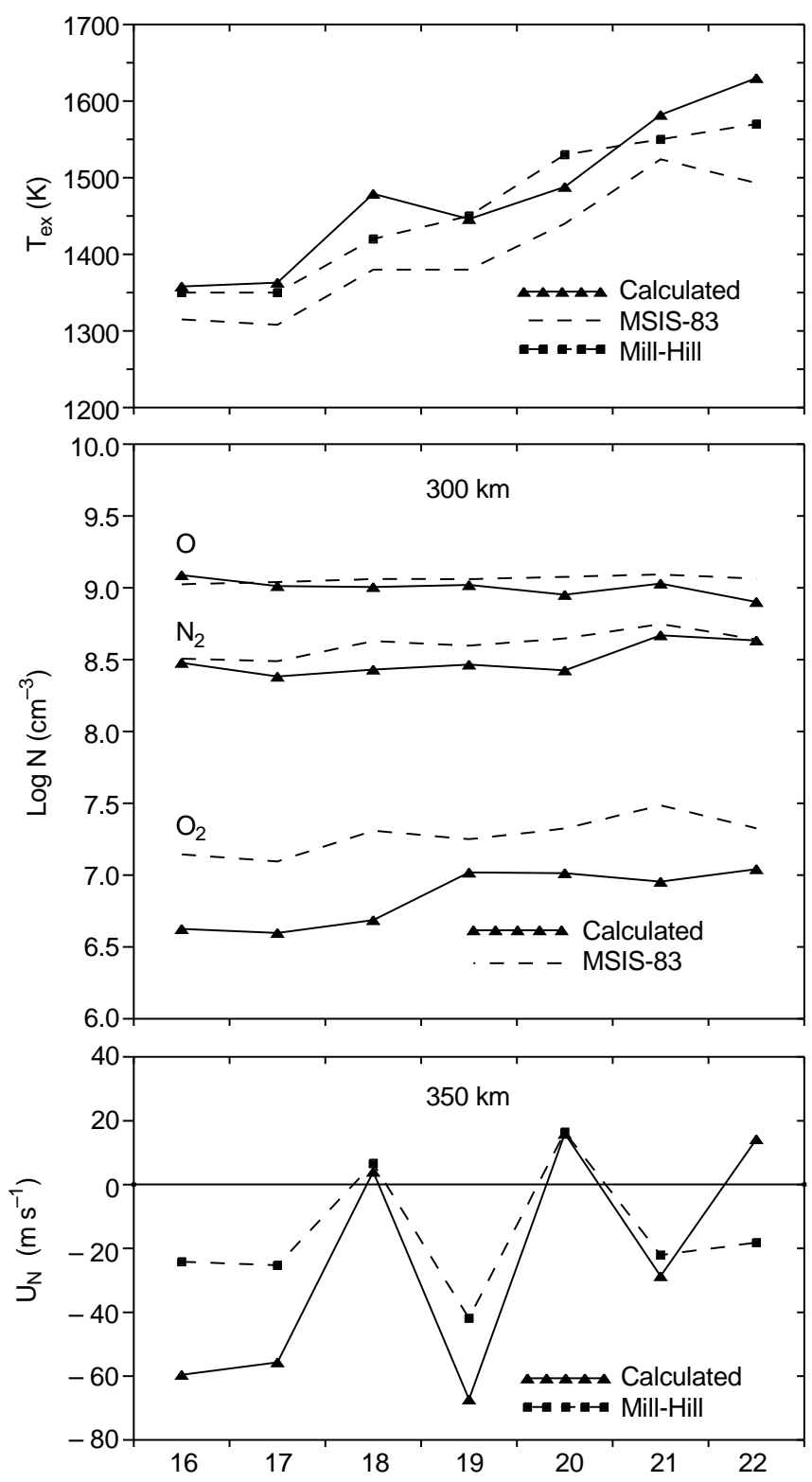

Fig. 6. Calculated (triangles), Millstone Hill estimated (squares) and MSIS-83 predicted (dashes) exospheric temperature $T_{\mathrm{ex}}$. Calculated (triangles) along with the MSIS-83 predicted (dashes) $\mathrm{O}, \mathrm{N}_{2}$ and $\mathrm{O}_{2}$ variations at $300 \mathrm{~km}$. Calculated values (triangles) in comparison with Millstone Hill estimates (squares) of meridional (along the magnetic meridian) thermospheric wind (positive to the south). Figures along the $\mathrm{x}$ axis (UT) are dates of March 1990 
Table 2. Calculated thermospheric parameters and MSIS-83 model predictions (second line) at the height of $h_{m} F 2$

\begin{tabular}{|c|c|c|c|c|c|c|c|}
\hline Date & $\begin{array}{l}h_{m} F 2 \\
(\mathrm{~km})\end{array}$ & $\begin{array}{l}\log [\mathrm{O}] \\
\left(\mathrm{cm}^{-3}\right)\end{array}$ & $\begin{array}{l}\log \left[\mathrm{O}_{2}\right] \\
\left(\mathrm{cm}^{-3}\right)\end{array}$ & $\begin{array}{l}\log \left[N_{2}\right] \\
\left(\mathrm{cm}^{-3}\right)\end{array}$ & $\begin{array}{l}\mathrm{S} \\
(\mathrm{K})\end{array}$ & $T_{e x}$ & $\begin{array}{l}\mathrm{W} \\
(\mathrm{m} / \mathrm{s})\end{array}$ \\
\hline \multicolumn{8}{|l|}{1990} \\
\hline Mar 16 & 309 & $\begin{array}{l}9.028 \\
8.964\end{array}$ & $\begin{array}{l}6.508 \\
7.026\end{array}$ & $\begin{array}{l}8.377 \\
8.402\end{array}$ & $\begin{array}{l}.017 \\
.017\end{array}$ & $\begin{array}{l}1358 \\
1315\end{array}$ & -13.8 \\
\hline Mar 17 & 308 & $\begin{array}{l}8.954 \\
8.979\end{array}$ & $\begin{array}{l}6.482 \\
6.975\end{array}$ & $\begin{array}{l}8.280 \\
8.384\end{array}$ & $\begin{array}{l}.017 \\
.018\end{array}$ & $\begin{array}{l}1363 \\
1308\end{array}$ & -8.1 \\
\hline Mar 18 & 328 & $\begin{array}{l}8.842 \\
8.889\end{array}$ & $\begin{array}{l}6.368 \\
6.971\end{array}$ & $\begin{array}{l}8.151 \\
8.333\end{array}$ & $\begin{array}{l}.016 \\
.017\end{array}$ & $\begin{array}{l}1479 \\
1380\end{array}$ & -3.2 \\
\hline Mar 19 & 311 & $\begin{array}{l}8.962 \\
9.002\end{array}$ & $\begin{array}{l}6.907 \\
7.136\end{array}$ & $\begin{array}{l}8.368 \\
8.496\end{array}$ & $\begin{array}{l}.016 \\
.017\end{array}$ & $\begin{array}{l}1446 \\
1380\end{array}$ & -12.6 \\
\hline Mar 20 & 353 & $\begin{array}{l}8.680 \\
8.801\end{array}$ & $\begin{array}{l}6.485 \\
6.784\end{array}$ & $\begin{array}{l}7.961 \\
8.174\end{array}$ & $\begin{array}{l}.015 \\
.016\end{array}$ & $\begin{array}{l}1488 \\
1440\end{array}$ & 5.1 \\
\hline Mar 21 & 340 & $\begin{array}{l}8.824 \\
8.881\end{array}$ & $\begin{array}{l}6.551 \\
7.072\end{array}$ & $\begin{array}{l}8.316 \\
8.384\end{array}$ & $\begin{array}{l}.015 \\
.015\end{array}$ & $\begin{array}{l}1582 \\
1524\end{array}$ & -7.3 \\
\hline Mar 22 & 380 & $\begin{array}{l}8.514 \\
8.639\end{array}$ & $\begin{array}{l}6.280 \\
6.492\end{array}$ & $\begin{array}{l}7.965 \\
7.910\end{array}$ & $\begin{array}{l}.016 \\
.015\end{array}$ & $\begin{array}{l}1630 \\
1493\end{array}$ & 15.9 \\
\hline
\end{tabular}

fixed height of $300 \mathrm{~km}$. The meridional (along the magnetic meridian) neutral wind $U_{N}$ is inferred from the vertical plasma drift $\mathrm{W}$ after subtraction of the component related to $\mathbf{E} \times \mathbf{B}$ plasma drift $\left(U_{N}=\left(W-V_{\perp N}\right.\right.$ $\cos I) / \sin I \cos I)$. This $U_{N}$ is shown in comparison with the Millstone Hill estimates at the height of $350 \mathrm{~km}$ in the bottom box of Fig. 6. The method of $U_{N}$ derivation at Millstone Hill is described by Buonsanto (1990) and Buonsanto et al. (1992a). The calculated $U_{N}$ repeats Millstone Hill day-to-day $U_{N}$, the relative variation being more poleward on March 16, 17 and 19, coincides on March 18 and 20, but differs in sign on March 22.

The results for neutral composition are given in Fig. 6 at a fixed height of $300 \mathrm{~km}$ for convenience, but more proper comparison should be made at the height of the F2-layer maximum (Table 2) rather than at a fixed height as this minimizes the effect of different neutral temperatures $T_{\mathrm{ex}}$.

\section{Discussion}

The analysis of the calculated $T_{\mathrm{ex}}$ (Fig. 6 and Table 2) shows that the $T_{\mathrm{ex}}$ elevation by $270 \mathrm{~K}$ during the period in question mostly reflects the solar activity level increase from $F_{10.7}=179.9$ on March 16 to $F_{10.7}=244.7$ on March 22. A similar $T_{\text {ex }}$ increase is seen in the Millstone Hill estimates. The same tendency gives MSIS-83, but it predicts that $T_{\mathrm{ex}}$ will decrease from March 21 to March 22 due to an $A_{p}$ index decrease from $A_{p}=76$ to 28 and underestimates $T_{\mathrm{ex}}$ by $137 \mathrm{~K}$. On the other hand, average differences for these three curves are less than $10 \%$ and within the limits of the experimental $T_{\mathrm{ex}}$ determination as well as the accuracy of the model predictions.

A comparison of the MSIS- 83 and the calculated absolute [O] concentrations gives a difference of $18 \%$ on average. This difference is much less than that which was found at Arecibo by Burnside et al. (1991a) and at Millstone Hill by Oliver and Glotfelty (1996). It should be recalled that all collision frequencies used in our calculations are taken from Banks and Kockarts (1973) and $v\left(O^{+}-O\right)$, in particular. But in recent works devoted to the incoherent scatter data analysis (Burnside et al., 1987, 1988; Buonsanto et al., 1989; Burnside et al., 1991b, a; Buonsanto et al., 1992a, b) it is suggested that this value should be increased by a factor of 1.7. The possible effect of such correction is discussed by Belley et al. (1992). They point out that the inferred atomic oxygen densities would have to be decreased by the same factor and this would contradict the CIRA-86 model predictions on [O]. A much lower factor of $1.2-1.4$ for the $v\left(O^{+}-O\right)$ collision frequency was recommended recently by Pesnell (1993); Reddy et al. (1994) and Davis et al. (1995). This is closer to the Banks and Kockarts (1973) value. In the recent publication by Oliver and Glotfelty (1996) on this problem they found, from an analysis of Millstone Hill observations, that the $\left(\mathrm{O}^{+}-\mathrm{O}\right)$ collision cross section is only $75 \%$ of the Banks' value. The results of our calculations do not show any necessity to change the Banks and Kockarts (1973) $\left(O^{+}-O\right)$ value, but simultaneous daytime incoherent scatter and satellite measurements of neutral composition or wind observations are required to clear up this question.

The MSIS-83 model atomic oxygen concentration virtually does not demonstrate any variation with solar and geomagnetic activity at a fixed height of $300 \mathrm{~km}$ (Fig. 6) while our calculations show a $30 \%$ decrease on March 22 with respect to the quiet reference day of March 17. This [O] decrease takes place despite the 270 $\mathrm{K}$ increase in $T_{\mathrm{ex}}$ and informs us of the absolute decrease in [O] abundance in the thermosphere on the day of disturbance. A more pronounced difference by a factor of 1.5 in [O] decrease between our calculations and MSIS-83 predictions takes place at the height of $h_{m} F 2$ (Table 2).

A $30 \%$ difference on average between the calculated and MSIS- 83 predicted $\left[N_{2}\right]$ concentrations takes place for the period in question (Fig. 6, Table 2), but this may be considered as a normal result. A comparison of $\left[N_{2}\right]$ measured on board the DE-2 satellite with MSIS-83 predictions gives a ratio of $0.5-0.9$ for quiet geomagnetic conditions (Hedin and Carignan, 1985). A two-fold increase in $\left[N_{2}\right]$ compared to the prestorm level takes place at $300 \mathrm{~km}$ on March 21 and 22 when the second geomagnetic storm was in progress. A very weak reaction to the first geomagnetic disturbance on March 18 is seen in [O] and $\left[N_{2}\right]$ variations. A general increase in $\left[\mathrm{O}_{2}\right]$ can be seen throughout the period in question, but the reliability of the calculated $\left[\mathrm{O}_{2}\right]$ is not too high as stressed by Mikhailov and Schlegel (1997).

The calculated at $350 \mathrm{~km}$ meridional (along the magnetic meridian) neutral wind $U_{N}$ (Fig. 6) is more positive (more equatorward) for disturbed days in accordance with the present-day understanding of the global circulation pattern. It is similar to Millstone Hill estimates except for the most disturbed day of March 22 when Millstone Hill analysis gives a northward $U_{N}$. The reason for this difference is not clear, but it requires a special analysis, outside the scope of this study. 
Let us analyze the ionospheric parameter variations given in Fig. 5. Daytime $N_{m} F 2$ in accordance with Rishbeth and Barron's (1960) concept is mostly controlled by the $\mathrm{q}\left(O^{+}\right) / \beta$ variation. The exospheric temperature $T_{\text {ex }}$ increase (Fig. 6) provides the general $h_{m} F 2$ elevation throughout the period in question, but day-today $h_{m} F 2$ relative changes are mostly governed by the vertical drift $\mathrm{W}$ variation. The vertical drift, $\mathrm{W}$ is seen to reflect the changes in the geomagnetic activity, being more positive for disturbed days, as it is mostly due to the thermospheric wind (Fig. 6) and to a less extent to electric fields. The effect of disturbances on March 18, 20 and 22 is clearly seen in the calculated vertical drift velocity $\mathrm{W}$ variations. The onset of the first disturbance on March 18 took place during daytime hours in the American longitudinal sector (Fig. 1). So, we can expect only vertical plasma drift increases due to the thermospheric circulation changes but not changes in [O] and $\left[N_{2}\right]$ concentrations (Mikhailov et al., 1995). This is a well-known concept of forbidden local time for the F2layer negative storm onset (Prölss and von Zahn, 1978). According to this concept, negative F2-layer storm effects do not appear as a rule at mid-latitudes for geomagnetic storm onsets in the daytime sector, especially for winter and equinox periods. This does take place in our calculations, so a small positive F2-layer storm effect should be totally attributed to the decrease of normal northward thermospheric wind (Fig. 6). A similar situation takes place on March 20, when the first step of the large geomagnetic storm (see Fig. 1) falls again in the daytime hours. Our calculations do not show any noticeable changes in $[\mathrm{O}]$ and $\left[N_{2}\right]$ concentrations for this period, but a very pronounced vertical drift increase does occur. This is the effect of the normal background (poleward) thermospheric circulation damped by the increased auroral heating. When the auroral heating is moderate, we have no changes of neutral composition at middle latitudes during winter and equinox periods, but an increase of vertical plasma drift only (Mikhailov and Skoblin, 1990; Mikhailov et al., 1995). Indeed, our calculations as well as Millstone Hill calculations give a small equatorward $U_{N}$ on these days (Fig. 6). This is in accordance with the Prölss (1980) concept that the daytime positive storm effects are not related to density changes but caused by ionization transport effects due to thermospheric winds (Prölss, 1991, 1993).

The $N_{m} F 2$ negative storm effect on March 21 and 22 results mostly from neutral composition changes in accordance with the present-day understanding of this phenomenon. The calculated $[\mathrm{O}]$ and $\left[N_{2}\right]$ concentrations as well as the exospheric temperature $T_{\mathrm{ex}}$ on March 21 are very close to the MSIS- 83 predictions (Fig. 6, see also $\mathrm{O} / N_{2}$ ratio in Fig. 5), so moderate daytime F2-layer storm effects may be explained with the help of empirical models such as MSIS-83.

The situation is different for March 22. The calculated $T_{\mathrm{ex}}$ is higher than the model one by $137 \mathrm{~K}$ (Table 2 ), the $\mathrm{O} / N_{2}$ ratio is less by 1.51 times at the height of $h_{m} F 2$ (Fig. 5), or by a factor of 1.43 at $300 \mathrm{~km}$. The $\mathrm{q}\left(O^{+}\right) / \beta$ ratios at $h_{m} F 2$ are very close for March 21 and
22 (Fig. 5), but despite the fact that the upward drift of $16 \mathrm{~m} / \mathrm{s}$ on March 22 helps to increase $N_{m} F 2$, the $N_{m} F 2$ decreases instead. This results from a strong $1.2 \times 10^{9} \mathrm{~cm}^{-2} \mathrm{~s}^{-1}$ outflow of $\mathrm{O}^{+}$ions from the F2-region (Fig. 5). It should be mentioned that even larger $O^{+}$ fluxes were measured at Millstone Hill for the disturbance on February 8, 1986 (Yeh and Foster, 1990). The overall agreement between calculated and observed $O^{+}$ fluxes at $600 \mathrm{~km}$ height is seen for the period in question (Fig. 5) and this gives an additional confirmation of the validity of our calculations.

The obtained results have shown that the selfconsistent approach to the $N_{e}(h)$ modelling in the ionospheric F-region can be successfully used for the analysis of both quiet and disturbed conditions. This was shown as well for more severe F2-layer storms by Mikhailov and Schlegel (1997); and Mikhailov and Foster (1997). The method gives reasonable neutral composition, temperature, wind and $\mathrm{O}^{+}$flux variations. The observed daytime moderate negative F2-layer storm effects in March 1990 can be totally explained using model MSIS-83 neutral composition for March 21, or slightly changed by a factor of $1.5 \mathrm{O} / N_{2}$ ratio for the stronger disturbance on March 22. This differs from the results of other analyses (Richards et al., 1989, 1994b) where much larger $\mathrm{O} / N_{2}$ ratio changes were suggested. No special consideration of vibrationally excited $\mathrm{N}_{2}$ effects is made in our method, but the laboratory measured by McFarland et al. $(1973)\left(O^{+}+N_{2}\right)$ reaction rate constant efficiently mimics the increase of this reaction rate due to $\mathrm{N}_{2}{ }^{*}$ at high level of solar activity. This was confirmed by the results of Mikhailov and Schlegel (1997); and Mikhailov and Foster (1997) analyses of disturbed periods during the phase of solar maximum. Recent laboratory measurements of the $\mathrm{O}^{+}+\mathrm{N}_{2}$ reaction rate constant (Hierl et al., 1997) confirm a steep increase of the reaction rate for temperatures higher than $1300 \mathrm{~K}$ due to $N_{2}$ vibrational excitation.

\section{Conclusions}

The self-consistent method of Mikhailov and Schlegel (1997) for day-time F2-layer modelling was applied to the analysis of Millstone Hill incoherent scatter observations during the storm period of March 16-22, 1990. The method allows us to calculate in a self-consistent way neutral composition and temperature, vertical plasma drift and $\mathrm{O}^{+}$ion outflow from the F2-region, i.e. the main aeronomic parameters responsible for the mid-latitude F2-layer formation. Earlier the method was developed and tested using day-time EISCAT observations. Now it is confirmed by the Millstone Hill data that the method can be successfully used for the analysis of other incoherent scatter observations both for quiet and disturbed conditions. The main results of our study may be listed as follows:

1. The F2-layer theoretical model being the core of the method enables us to fit calculated to observed $N_{e}(\mathrm{~h})$ 
profiles with great accuracy in the whole range of heights above $150 \mathrm{~km}$ for both geomagnetically quiet and disturbed days.

2. The calculated exospheric temperature $T_{\mathrm{ex}}$ shows an overall increase by $270 \mathrm{~K}$ from March 16 to March 22 resulting from the general increase of the solar activity level during the period in question. The $T_{\mathrm{ex}}$ variations are close to Millstone Hill estimates, and both are higher than the MSIS- 83 predictions by $50-130 \mathrm{~K}$.

3 . The calculated atomic oxygen shows a $30 \%$ decrease at $300 \mathrm{~km}$ on March 22 relative to the quiet time prestorm period. This [O] decrease takes place despite the $270 \mathrm{~K}$ increase in $T_{\mathrm{ex}}$ and relates to the absolute decrease in $[\mathrm{O}]$ abundance in the thermosphere on the disturbed day in accordance with the present-day understanding of the physical processes in the disturbed thermosphere. The MSIS- 83 model, on the contrary, predicts a small increase in $[\mathrm{O}]$.

4. A two-fold increase in $\left[N_{2}\right]$ concentration at $300 \mathrm{~km}$ compared to the prestorm level takes place on March 21,22 when the second geomagnetic storm was in progress. Only a small reaction to the first geomagnetic disturbance on March 18 and the initial phase of the second storm on March 20 was found in $[\mathrm{O}]$ and $\left[N_{2}\right]$ variations in accordance with the forbidden time for the F2-layer negative storm phase onset concept.

5. The inferred from plasma vertical drift $\mathrm{W}$ meridional neutral thermospheric wind clearly demonstrates the dependence on the geomagnetic activity level being more equatorward for disturbed days. This tendency is more pronounced in our calculations than in Millstone Hill estimates of $U_{N}$.

6. Small positive F2-layer storm effects with simultaneous $N_{m} F 2$ and $h_{m} F 2$ increase observed on March 18 and 20 are totally attributed to the decrease of the northward neutral wind due to the increase of auroral heating but not to changes of neutral composition. This takes place at mid-latitudes when the storm onset falls into day-time hours.

7. The observed daytime negative F2-layer storm effects on March 21 and 22 are produced by neutral composition changes along with increased $\mathrm{O}^{+}$ions outflow from the F2-region. They can be totally explained using model MSIS-83 neutral composition for March 21, or slightly decreased by a factor of $1.5 \mathrm{O} / \mathrm{N} 2$ ratio for the stronger disturbance on March 22. This is different from the results of other F2-layer negative storm effect considerations where much a larger $\mathrm{O} / N_{2}$ ratio decrease was required to explain the observed decrease in $N_{m} F 2$. A plausible explanation to this difference is seen in our self-consistent approach which provides internal consistency for the main aeronomic parameters.

Acknowledgements. The authors are grateful to M. Buonsanto (Massachusetts Institute of Technology, Westford) for providing the Millstone Hill observations and many fruitful discussions. We also thank K. Schlegel (MPAE, Lindau-Katlenburg) for making available his program for radar ACF calculation. This study is part of the research projects supported by the Deutsche Agentur für Raumfahrtangelegenheiten (DARA) $\mathrm{GmbH}$ under grant $50 \mathrm{QL}$ 92060.

Topical Editor D. Alcayde' thanks M. Buonsanto and another referee for their help in evaluating this paper.

\section{References}

Alcayde, D., Incoherent scatter data related to thermospheric modelling, Space Rese. 19, 211-229, 1979.

Alcayde, D., and J. Fontanari, High-latitude neutral atmosphere temperature and concentration measurements from the first EISCAT incoherent scatter observations. Ann. Geophysicae, 38, 473-480, 1982.

Alcayde, D., and J. Fontanari, Neutral temperature and winds from EISCAT CP-3 observations, J. Atoms. Terr. Phys., 48, 931-947, 1986.

Alcayde, D., P. Bauer, and J. Fontanari, Long-term variations of thermospheric temperature and composition, J. Geophys. Res., 79, 629-637, 1974.

Banks, P., and G. Kockarts, Aeronomy, Academic Press, New York, 1973.

Bates, D. R., Some problems concerning the terrestrial atmosphere above $100 \mathrm{~km}$ level, Proc. R. Soc. London, A253, 451-462, 1959.

Blelly, P. L., J. Fontanari, D. Alcayde, J. Wu, M. Blanc, and T. L. Hanse, Observations of the structure and vertical transport of the polar upper ionosphere with the EISCAT-VHF radar, Ann. Geophysicae, 10, 394-406, 1992.

Buonsanto, M., Observed and calculated F2 peak heights and derived meridional winds at mid-latitudes over a full solar cycle, J. Atmos. Terr. Phys., 52, 223-240, 1990.

Buonsanto, M., Millstone Hill incoherent scatter F region observations during the disturbances of June 1991, J. Geophys. Res., 100, 5743-5755, 1995.

Buonsanto, M., J. Foster, and D. Sipler, Observations from Millstone Hill during the geomagnetic disturbances of March and April 1990, J. Geophys. Res., 97, 1225-1243, 1992a.

Buonsanto, M. J., J. E. Salah, K. L. Miller, W. L. Oliver, R. G. Burnside, and P. G. Richards, Observations of neutral circulation at mid-latitudes during the equinox transition study, J. Geophys. Res., 94, 16.987-16.997, 1989.

Buonsanto, M. J., Y.-K. Tung, and D. P. Sipler, Neutral atomic oxygen density from nighttime radar and optical wind measurements at Millstone Hill, J. Geophys. Res., 97, 8673-8679, $1992 b$.

Burnside, R. G., C. A. Tepley, and V. P. Wickwar, The $O^{+}-\mathrm{O}$ collision cross-section: can it be inferred from aeronomical measurements?, Ann. Geophysicae, 5, 343-350, 1987.

Burnside, R. G., M. P. Sulzer, and J. C. G. Walker, Determination of the thermospheric temperatures and neutral densities at Arecibo from the ion energy balance, J. Geophys. Res., 93, 8642-8650, 1988.

Burnside, R. G., C. A. Tepley, and M. P. Sulzer, World day observations at Arecibo: 1985 to 1989, J. Geophys. Res., 96, 3691-3710, 1991a.

Burnside, R. G., C. A. Tepley, M. P. Sulzer, T. F. Fuller-Rowell, D. G. Torr, and R. G. Roble, The neutral thermosphere at Arecibo during geomagnetic storms, J. Geophys. Res., 96, 12891301, 1991b.

Davis, C. J., A. D. Farmer, and A. Aruliah, An optimised method for calculating the $O^{+}-O$ collision parameter from aeronomic measurements, Ann. Geophysicae, 13, 541-550, 1995.

Evans, J. V., W. L. J. Oliver, and J. E. Salah, Thermospheric properties as deduced from incoherent scatter measurements, J. Atoms. Terr. Phys., 41, 259-278, 1979.

Flå, T., A. Skoelv, U. P. Lovhaug, and A. Brekke, Thermospheric wind measurements with EISCAT, J. Atoms. Terr. Phys., 48, 949-958, 1986.

Förster, M., N. Jakowski, A. Best, and J. Smilauer, Plasmaspheric response to the geomagnetic storm period March 20-23, 1990, observed by the Activity (Magion-2) satellite, Can. J. Phys., 70, 569-574, 1992.

Förster, M., V. V. Mikhailov, A. V. Mikhailov, and J. Smilauer, Ion composition measured on board the Active satellite in the European sector during April 10-12, 1990 geomagnetic storm, Ann. Geophysicae, 13, 608-616, 1995. 
Ganguly, S., J. C. G. Walker, and H. Rishbeth, The dynamic F2layer over Arecibo, J. Atmos. Terr. Phys., 42, 553-562, 1980.

Glatthor, N., and R. Hernandez, Temperature anisotropy of drifting ions in the auroral F-region, observed by EISCAT. J. Atmos. Terr. Phys., 52, 545-560, 1990.

Hagan, M. E., and W. L. Oliver, Solar cycle variability of exospheric temperature at Millstone Hill between 1970 and 1980, J. Geophys. Res., 90, 12.265-12.270, 1985.

Hedin, A. E., A revised thermospheric model base on massspectrometer and incoherent scatter data MSIS-83, J. Geophys. Res., 88, 10.170-10.188, 1983.

Hedin, A. E., MSIS-86 thermospheric model, J. Geophys. Res., 92(A5), 4649-4662, 1987.

Hedin, A. E., and G. R. Carignan, Morphology of thermospheric composition variations in the quiet polar thermosphere from Dynamic Explorer measurements, J. Geophys. Res., 90, 52695277, 1985.

Hierl, P. M., I. Dotan, J. V. Seeley, J. M. Van Doren, R. A. Morris, and A. A. Viggiano, Rate constants for the reactions of $O^{+}$with $\mathrm{N}_{2}$ and $\mathrm{O}_{2}$ as a function of temperature (300-1800 K), J. Chem. Phys. 106, 3540-3544, 1997.

Ivanov-Kholodny, G. S., and A. V. Mikhailov, The prediction of ionospheric conditions, Reidel, Dordrecht, 1986.

Kirkwood, S., P. N. Collis, and W. Schmidt, Calibration of electron densities for EISCAT UHF radar, J. Atoms. Terr. Phys., 48, 773-775, 1986.

Lathuillere, C., G. Lejeune, and W. Kofman, Direct measurements of ion composition with EISCAT in the high-latitude F1 region, Radio Sci., 18, 887-893, 1983.

McFarland, M., D. L. Albritton, F. C. Fehsenfeld, E. E. Ferguson, and A. L. Schmelekopf, Flow-drift technique for ion mobility and ion-molecular reaction rate constant measurements. II. Positive ion reactions of $\mathrm{N}^{+}, \mathrm{O}_{2}$ and $\mathrm{O}^{+}$, and $\mathrm{N}_{2}^{+}$with $\mathrm{O}^{+}$with $\mathrm{N}_{2}$ from thermal to $2 \mathrm{eV}$, J. chem. Phys., 59, 6620-6628, 1973.

Mikhailov, A. V., and J. C. Foster, Daytime thermosphere variations above Millstone Hill during severe geomagnetic storms, J. Geophys. Res., 102, 1997 in press.

Mikhailov, A. V., and K. Schlegel, Self-consistent modelling of the daytime electron density profile in the ionospheric F-region, Ann. Geophysicae, 15, Mikhailov, A.V. and Schlegel, K., 1997: 15, 3, 314-326, 1997

Mikhailov, A. V., and M. G. Skoblin, Longitudinal variations of the positive phase of the ionospheric storm of January 25-27, 1974 from the viewpoint of its formative mechanism, Geomagn. Aeron, 30, 648-652, 1990.

Mikhailov, A. V., M. G. Skoblin, and M. Förster, Day-time F2layer positive storm effect at middle and lower latitudes, Ann. Geophysicae, 13, 532-540, 1995.

Oliver, W. L., Incoherent scatter radar studies of the daytime middle thermosphere, Ann. Geophysicae, 35, 121-139, 1979.

Oliver, W. L., Improved Millstone Hill exospheric temperature measurements. Evidence for a seasonal variation of the magnetic activity effects, J. Geophys. Res., 85, 4237-4247, 1980.

Oliver, W. L., Neutral and ion composition changes in the F region over Millstone Hill during the equinox transition study, J. Geophys. Res., 95, 4129-4134, 1990.

Oliver, W. L., and K. Glotfelty, $\mathrm{O}^{+}-\mathrm{O}$ collision cross section and long-term $\mathrm{F}$ region $\mathrm{O}$ density variations deduced from the ionospheric energy budget, J. Geophys. Res., 101, 21, 76921,784, 1996.

Pavlov, A. V., The role of vibrationally excited nitrogen in the formation of the mid-latitude negative ionospheric storms, Ann. Geophysicae, 12, 554-564, 1994.

Pavlov, A. V., and M. J. Buonsanto, Comparison of model electron densities and temperatures with Millstone Hill observations during undisturbed period and the geomagnetic storms of 16-23 March and 6-12 April 1990, Ann. Geophysicae, 15, 327-344, 1997.

Pesnell, W. D., Momentum transfer collision frequency of $\mathrm{O}^{+}-O$, Geophys. Res. Lett., 20, 1343-1346, 1993.

Prölss, G. W., Magnetic storm associated perturbations of the upper atmosphere: recent results obtained by satellite-borne gas analyzers, Rev. Geophys. Space Phys., 18, 183-202, 1980.

Prölss, G. W., Thermosphere-ionosphere coupling during disturbed conditions, J. Geomag. Geoelectr., 43, 537-549, 1991.

Prölss, G. W., Common origin of positive ionospheric storms at middle latitudes and the geomagnetic activity effect at low latitudes, J. Geophys. Res., 98, 5981-5991, 1993.

Prölss, G. W., and U. von Zahn, On the local time variation of atmospheric-ionospheric disturbances, Space Res., 18, 159-162, 1978.

Reddy, C. A., W. R. Hoegy, W. D. Pesnell, and C. O. Hines, Accuracy of $O^{+}-O$ collision cross-section deduced from ionosphere-thermosphere observations, Geophys. Res. Lett., 21, 2429-2432, 1994.

Richards, P. G., D. G. Torr, M. J. Buonsanto, and K. L. Miller, The behaviour of the electron density and temperature at Millstone Hill during the equinox transition study September 1984. J. Geophys. Res., 94, 16.969-16.975, 1989.

Richards, P. G., J. A. Fenelly, and D. G. Torr, EUVAC: a solar EUV flux model for aeronomic calculations, J Geophys. Res., 99, 8981-8992, 1994a.

Richards, P. G., D. G. Torr, M. J. Buonsanto, and D. Sipler, Ionospheric effects of the March 1990 magnetic storm: comparison of theory and measurement, J. Geophys. Res., 99, 23,359-23,365, 1994b.

Richards, P.G., D. G. Torr, B. W. Reinisch, R. R. Gamache, and P.J. Wilkinson, F2 peak electron density at Millstone Hill and Hobart: comparison of theory and measurement at solar maximum, J. Geophys. Res., 99, 15.005-15.016, 1994c.

Rishbeth, H., and D. W. Barron, Equillibrium electron distributions in the ionospheric F2-layer, J. Atoms. Terr. Phys., 18, 231-252, 1960.

Salah, J. E., J. V. Evans, and R. H. Wand, Seasonal variation in the thermosphere above Millstone Hill, Radio Sci., 9, 231-238, 1974.

Waldteufel, P., Combined incoherent-scatter F1-region observations, J. Geophys. Res., 76, 6995-6999, 1971.

Winser, K. J., A. D. Farmer, D. Rees, and A. Aruliah, Ion-neutral dynamics in the high-latitude ionosphere: first results from the INDI experiment, J. Atmos. Terr. Phys., 50, 369-377, 1988.

Winser, K. J., M. Lockwood, G. O. L. Jones, and H. Rishbeth, Measuring ion temperatures and studying the ion energy balance in the high-latitude ionosphere, J. Atmos. Terr. Phys., 52, 501-517, 1990.

Yeh, H.-C, and J. C. Foster, Storm time heavy ion outflow at midlatitude, J. Geophys. Res., 95, 7881-7891, 1990. 